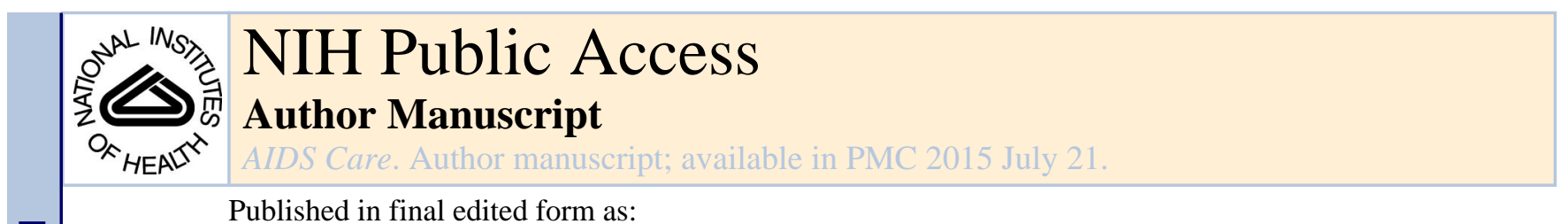

Published in final edited form as:

AIDS Care. 2014 ; 26(12): 1619-1624. doi:10.1080/09540121.2014.938013.

\title{
Levels of alcohol use and history of HIV testing among female sex workers in Mombasa, Kenya
}

\author{
Angela M. Bengtson ${ }^{a,}{ }^{,}$, Kelly L’Engle ${ }^{b}$, Peter Mwarogo ${ }^{c}$, and Nzioki King'ola ${ }^{d}$ \\ aDepartment of Epidemiology, University of North Carolina, Chapel Hill, NC, USA \\ bSocial and Behavioral Health Sciences Department, FHI 360, Research Triangle Park, NC, USA \\ 'FHI 360, Nairobi, Kenya \\ dInternational Centre for Reproductive Health, Mombasa, Kenya
}

\begin{abstract}
HIV testing is a critical first step to accessing HIV care and treatment, particularly for high-risk groups such as female sex workers (FSWs). Alcohol use may be a barrier to accessing HIV services, including HIV testing. We analyzed data from a cross-sectional survey of 818 FSWs in Mombasa, Kenya, and estimated the association between different levels of alcohol use and having never tested for HIV. In multivariable analyses, higher levels of alcohol consumption were associated with having never tested for HIV (PR 1.60; 95\% CI: 1.07, 2.40). Future interventions should explore whether reducing harmful drinking improves HIV testing among FSWs.
\end{abstract}

\section{Keywords}

HIV testing; alcohol use; female sex workers; HIV prevention

\section{Introduction}

HIV testing is the critical first step to accessing HIV care and treatment (Dilernia et al., 2013; Kilmarx \& Mutasa-Apollo, 2013). Timely linkage to care and early initiation of antiretroviral therapy (ART) are essential to achieve virologic suppression and reduction in HIV transmission (Cohen et al., 2011; Govindasamy et al., 2011; MacPherson et al., 2012; Rosen \& Fox, 2011). Test-and-treat HIV prevention strategies are increasingly being considered for a number of high-risk populations, including female sex workers (FSWs; Delva et al., 2012). For test-and-treat strategies to be effective, barriers to HIV testing need to be addressed.

FSWs in sub-Saharan Africa (SSA) are widely recognized as a critical population to target for HIV testing and prevention services (Braunstein et al., 2011; World Health Organization, 2005). The prevalence of HIV among FSWs in Mombasa is estimated between 30-35\% (Luchters et al., 2010; van der Elst et al., 2009), compared with 4.3\% among the general

(C) 2014 Taylor \& Francis

*Corresponding author. abengtso@live.unc.edu. 
population (National AIDS and STI Control Programme, Ministry of Health, Kenya, 2013). Nearly $14 \%$ of new HIV infections are estimated to be attributable to sex with FSWs in Kenya (Kenya National AIDS Control Council, 2009). Despite the need for HIV testing among FSWs, voluntary counseling and testing has been reported as low as 7\% (Abdelrahim, 2010). In Kenya, nearly $60 \%$ of FSWs report not knowing their HIV status (Luchters et al., 2008). Younger age, less education, and not having a regular sexual partner have been associated with decreased HIV testing among FSWs in Asia (Hong et al., 2012; Xu et al., 2011). Less is known about factors associated with HIV testing among FSWs in SSA.

Alcohol use among FSWs is high and has long been identified as a contributor to risky sexual behavior (Asiki et al., 2011; Kalichman, Simbayi, Kaufman, Cain, \& Jooste, 2007; World Health Organization, Department of Mental Health and Substance Dependence, 2000; Zablotska et al., 2006). In Kenya, 30\% of FSWs report drinking daily (Chersich et al., 2007). Alcohol use has been associated with an increased number of sexual partners, unprotected sex, inconsistent condom use, and sexual violence (Coldiron et al., 2008; Pitpitan et al., 2012; Weiser et al., 2006). Outcomes across the HIV care continuum, including sub-optimal ART adherence and loss to follow-up from HIV care, have also been linked to alcohol use (Deribe, Hailekiros, Biadgilign, Amberbir, \& Beyene, 2008; Kenya et al., 2013; Nakimuli-Mpungu et al., 2012; Ohl et al., 2013). Alcohol use has previously been associated with HIV testing behavior and may play a role in failure to seek HIV testing (Fatch et al., 2012; Luseno \& Wechsberg, 2009). However, little is known about the relationship between alcohol use and HIV testing among FSWs in SSA.

The goal of the present analysis was to investigate the association between levels of alcohol use and never having tested for HIV among FSWs who use alcohol in Mombasa, Kenya.

\section{Methods}

Data for the present analysis come from 818 women who completed the baseline interview of a longitudinal intervention to reduce alcohol use among FSWs in Mombasa, Kenya between October 2011 and October 2012. FSWs were enrolled from three community dropin centers that provide condoms and routine HIV/sexually transmitted infection (STI) testing through US Agency for International Development's (USAID) AIDS, Population and Health Integrated Assistance Plus (APHIAplus) program. Participants were randomized to either a brief alcohol-reduction intervention or nutritional counseling and followed for 12 months. The goal of the intervention was to reduce alcohol consumption among FSWs; therefore, only women who regularly drank alcohol but were not alcohol dependent, self-reported being a FSW, were $\geq 18$ years of age, and lived in Mombasa were eligible for inclusion in the intervention and present analysis. Participants received HIV and STI testing as part of the intervention at baseline, 6 and 12 months. Women were asked about HIV testing frequency regardless of HIV status. HIV incidence was a primary endpoint of the main study; therefore, lab-confirmed HIV status was prioritized and information on knowledge of HIV status was not collected. Baseline HIV status was used as a surrogate for knowledge of HIV status. All participants provided written informed consent and the study was approved 
by the ethical review boards of the Kenyatta National Hospital in Kenya and FHI360 in the USA

\section{Measures}

Alcohol use during the past year was measured using the WHO-endorsed 10-item Alcohol Use Disorders Identification Test (AUDIT; Babor \& Higgins-Biddle, 2001), which has been previously validated in Kenya (Saunders, Aasland, Babor, de la Fuente, \& Grant, 1993). Women enrolled in the intervention had AUDIT scores from 7 to 19. In the present analysis, we used previously established definitions (Babor \& Higgins-Biddle, 2001; MacAskill et al., 2011; Miller, Zweben, DiClemente, \& Rychtarik, 1992) to categorized alcohol use into higher "harmful" alcohol use (AUDIT score 16-19), compared to lower "hazardous" alcohol use (AUDIT score 7-15; referent). Whether a participant had tested for HIV prior to enrolling in the study was self-reported at baseline. Confounders of interest included baseline age, education, number of children, number of sexual partners in the last 7 days, number of years as a FSW, and HIV status. Categorization of age and number of years as a FSW was based on quartiles. Very few women reported being currently married (3\%) or living with a partner $(8 \%)$; therefore, these variables were not included as confounders.

\section{Statistical analysis}

We used log-binomial and Poisson models with a robust variance estimator (Barros \& Hirakata, 2003) to estimate the association between alcohol use and having never tested for HIV. Multivariable estimates were obtained using a Poisson model, due to convergence issues with the log-binomial model. In addition to all confounders, multivariable estimates included adjustment for the drop-in center attended. We conducted a sensitivity analysis restricted to HIV-uninfected women at baseline since knowledge of being HIV-infected could impact both testing behavior and alcohol consumption. All analyses were conducted using Stata 11 (StataCorp, College Station, TX).

\section{Results}

Women included in the study overall were young in age (30\% aged 18-23); however, a higher proportion of women who had never tested for HIV were aged 31-54 (38\% compared to $23 \%$ ). The majority of women had little education (55\% never attended school or only primary school) and had at least one child $(81 \%)$. A higher proportion of women with no prior HIV testing reported $>7$ years of sex work, compared to women who had tested for HIV (31\% compared to 24\%). A higher proportion of HIV-infected women had never tested for HIV (29\% compared to $19 \%$ of women who had tested; Table 1).

The prevalence of HIV among all FSWs in the study was 20\%. Approximately, $11 \%$ of FSWs reported never having been tested for HIV prior to enrolling in the study. Among FSWs who had ever been tested, $45 \%$ reported testing every 3 months or more, $15 \%$ reported testing every 6 months, $12 \%$ reported testing every $1-3$ years, and $16 \%$ reported testing only once.

In multivariable analyses, women who reported harmful alcohol consumption were 1.60 (95\% CI: 1.07, 2.40) times as likely to have never tested for HIV, compared to women with 
hazardous alcohol consumption. Being age 31 or older was independently associated with never having tested for HIV (PR 1.98; 95\% CI: 1.06, 3.70), while having at least one child (PR 0.39; 95\% CI: 0.24, 0.64) was associated with previous HIV testing (Table 2). In the sensitivity analysis restricted to HIV-uninfected women, the association between harmful drinking and having never tested for HIV was similar (PR 1.64; 95\% CI: 1.00, 2.69).

\section{Discussion}

In this population of FSWs who consume alcohol, women who reported higher harmful drinking were significantly more likely to have never tested for HIV, compared to women who reported lower hazardous drinking. These results are consistent with previous evidence suggesting that alcohol use is associated with HIV testing behavior for women in SSA (Fatch et al., 2012; Luseno \& Wechsberg, 2009). While the cross-sectional nature of our study precludes attributing causality, our results suggest that FSWs with harmful alcohol use may be more likely to have never tested for HIV.

Increasingly, alcohol use has been recognized as an important factor for a range of HIV outcomes, including HIV testing (Fatch et al., 2012; Gari et al., 2013; Peltzer \& Mlambo, 2010), accessing ART(Arasteh \& Des Jarlais, 2009) and ART adherence (Kenya et al., 2013; Lyimo et al., 2012; Nakimuli-Mpungu et al., 2012; Ohl et al., 2013). Brief interventions to reduce alcohol use and risky sexual behaviors, paired with HIV testing, have shown promise in the short term (Edelman et al., 2012). However, interventions with longer follow-up are needed to determine whether reducing alcohol use impacts HIV testing and sexual risk behaviors over time.

Older age has previously been associated with having received an HIV test among women in Kenya (Cherutich et al., 2012). In our study, older age was independently associated with having never tested for HIV, suggesting that efforts to test FSWs may be missing older FSWs. Having a child was associated with prior HIV testing, likely due to being tested during antenatal care (Cherutich et al., 2012; MacPhail, Pettifor, Moyo, \& Rees, 2009). The relationship between alcohol use and HIV testing did not differ meaningfully when analyses were restricted to HIV-uninfected women, which may reflect the fact that HIV-infected women were unaware of their status prior to study enrollment.

Our study has several strengths and limitations. Strengths include the large sample of a highrisk population of FSWs attending drop-in centers in Kenya and the use of a validated measure of alcohol use. Limitations include the restricted range of alcohol use (AUDIT 719), the fact that alcohol use in the previous 12 months may not impact lifetime HIV testing behavior, inability to draw causal inference due to the cross-sectional design and use of HIV status as a surrogate for knowledge of HIV status.

HIV testing is a critical early step to accessing HIV care and treatment and is of particular importance for high-risk populations, such as FSW. In order to be effective, interventions to improve HIV testing need to target individuals least likely to get tested. In our analyses, individuals with higher levels of drinking were more likely to have never been tested for 
HIV. Future interventions to improve HIV testing among FSWs should consider targeting individuals with higher levels of alcohol use.

\section{Acknowledgments}

The authors thank Debra H. Weiner, Betsy Tolley, and Allison Prickett for their helpful comments in the development of this manuscript.

Funding

This research was supported by the President's Emergency Plan for AIDS Relief (PEPFAR) through the USAID under the terms of [grant number AID-623-A-11-00007]. Ms Bengtson was supported by a fellowship through the University of North Carolina, Chapel Hill and FHI 360. The views expressed in this document are those of the authors and do not necessarily reflect those of FHI 360 or the funding agencies.

\section{References}

Abdelrahim MS. HIV prevalence and risk behaviors of female sex workers in Khartoum, north Sudan. AIDS (London, England). 2010; 24(2):S55-S60.10.1097/01.aids.0000386734.79553.9a

Arasteh K, Des Jarlais DC. HIV testing and treatment among at-risk drinking injection drug users. Journal of the International Association of Physicians in AIDS Care (Chicago, IL: 2002). 2009; 8:196-201.10.1177/1545109709336222

Asiki G, Mpendo J, Abaasa A, Agaba C, Nanvubya A, Nielsen L, Kamali A. HIV and syphilis prevalence and associated risk factors among fishing communities of lake Victoria, Uganda. Sexually Transmitted Infections. 2011; 87:511-515.10.1136/sti.2010.046805 [PubMed: 21835763]

Babor, TF.; Higgins-Biddle, JC. Brief intervention for hazardous and harmful drinking. A manual for use in primary care. 2001. Retrieved July 30, 2013, from http://whqlibdoc.who.int/hq/2001/ who_msd_msb_01.6b.pdf

Barros AJ, Hirakata VN. Alternatives for logistic regression in cross-sectional studies: An empirical comparison of models that directly estimate the prevalence ratio. BMC Medical Research Methodology. 2003; 3(1):21.10.1186/1471-2288-3-21 [PubMed: 14567763]

Braunstein SL, Ingabire CM, Geubbels E, Vyankandondera J, Umulisa MM, Gahiro E, van de Wijgert JH. High burden of prevalent and recently acquired HIV among female sex workers and female HIV voluntary testing center clients in Kigali, Rwanda. PloS One. 2011; 6:e24321.10.1371/ journal.pone.0024321 [PubMed: 21949704]

Chersich MF, Luchters SMF, Malonza IM, Mwarogo P, King'ola N, Temmerman M. Heavy episodic drinking among Kenyan female sex workers is associated with unsafe sex, sexual violence and sexually transmitted infections. International Journal of STD \& AIDS. 2007; 18:764769.10.1258/095646207782212342 [PubMed: 18005511]

Cherutich P, Kaiser R, Galbraith J, Williamson J, Shiraishi RW, Ngare C. KAIS Study Group. Lack of knowledge of HIV status a major barrier to HIV prevention, care and treatment efforts in Kenya: Results from a nationally representative study. PloS One. 2012; 7:e36797.10.1371/journal.pone. 0036797 [PubMed: 22574226]

Cohen MS, Chen YQ, McCauley M, Gamble T, Hosseinipour MC, Kumarasamy N. HPTN 052 Study Team. Prevention of HIV-1 infection with early antiretroviral therapy. The New England Journal of Medicine. 2011; 365:493-505.10.1056/NEJMoa1105243 [PubMed: 21767103]

Coldiron ME, Stephenson R, Chomba E, Vwalika C, Karita E, Kayitenkore K, Haworth A. The relationship between alcohol consumption and unprotected sex among known HIV-discordant couples in Rwanda and Zambia. AIDS and Behavior. 2008; 12:594-603.10.1007/ s10461-007-9304-x [PubMed: 17705032]

Delva W, Eaton JW, Meng F, Fraser C, White RG, Vickerman P, Hallett TB. HIV treatment as prevention: Optimising the impact of expanded HIV treatment programmes. PLoS Medicine. 2012; 9:e1001258.10.1371/journal.pmed.1001258 [PubMed: 22802738] 
Deribe K, Hailekiros F, Biadgilign S, Amberbir A, Beyene BK. Defaulters from antiretroviral treatment in Jimma University specialized hospital, southwest Ethiopia. Tropical Medicine and International Health. 2008; 13:328-333.10.1111/j.1365-3156.2008.02006.x [PubMed: 18298607]

Dilernia DA, Monaco DC, Cesar C, Krolewiecki AJ, Friedman SR, Cahn P, Salomon H. Estimation of HIV-testing rates to maximize early diagnosis-derived benefits at the individual and population level. PloS One. 2013; 8(1):e53193.10.1371/journal.pone.0053193 [PubMed: 23308161]

Edelman EJ, Dinh A, Radulescu R, Lurie B, D’Onofrio G, Tetrault JM, Fiellin LE. Combining rapid HIV testing and a brief alcohol intervention in young unhealthy drinkers in the emergency department: A pilot study. The American Journal of Drug and Alcohol Abuse. 2012; 38:539_ 543.10.3109/00952990.2012.701359 [PubMed: 22794939]

Fatch R, Bellows B, Bagenda F, Mulogo E, Weiser S, Hahn JA. Alcohol consumption as a barrier to prior HIV testing in a population-based study in rural Uganda. AIDS and Behavior. 2012; 17:1713-1723.10.1007/s10461-012-0282-2 [PubMed: 22878790]

Gari S, Doig-Acuña C, Smail T, Malungo JR, Martin-Hilber A, Merten S. Access to HIV/AIDS care: A systematic review of socio-cultural determinants in low and high income countries. BMC Health Services Research. 2013; 13:198.10.1186/1472-6963-13-198 [PubMed: 23714167]

Govindasamy D, van Schaik N, Kranzer K, Wood R, Mathews C, Bekker LG. Linkage to HIV care from a mobile testing unit in South Africa by different CD4 count strata. Journal of Acquired Immune Deficiency Syndromes (1999). 2011; 58:344-352. [PubMed: 21836524]

Hong Y, Zhang C, Li X, Fang X, Lin X, Zhou Y, Liu W. HIV testing behaviors among female sex workers in southwest china. AIDS and Behavior. 2012; 16(1):44-52.10.1007/s10461-011-9960-8 [PubMed: 21538081]

Kalichman SC, Simbayi LC, Kaufman M, Cain D, Jooste S. Alcohol use and sexual risks for HIV/ AIDS in sub-Saharan Africa: Systematic review of empirical findings. Prevention Science. 2007; 8:141-151.10.1007/s11121-006-0061-2 [PubMed: 17265194]

Kenya National AIDS Control Council. Kenya national AIDS strategic plan 2009/10-2012/13: Delivering on universal access to services. 2009. Retrieved July 30, 2013, from http:// www.aidstar-one.com/sites/default/files/prevention/resources/national_strategic_plans/ Kenya_09-13.pdf

Kenya S, Chida N, Jones J, Alvarez G, Symes S, Kobetz E. Weekending in PLWH: Alcohol use and ART adherence, a pilot study. AIDS and Behavior. 2013; 17(1):61-67.10.1007/s10461-012-0307x [PubMed: 22961583]

Kilmarx PH, Mutasa-Apollo T. Patching a leaky pipe: The cascade of HIV care. Current Opinion in HIV and AIDS. 2013; 8(1):59-64. [PubMed: 23211779]

Luchters S, Chersich MF, Rinyiru A, Barasa MS, King'ola N, Mandaliya K, Temmerman M. Impact of five years of peer-mediated interventions on sexual behavior and sexually transmitted infections among female sex workers in Mombasa, Kenya. BMC Public Health. 2008; 8(1): 143.10.1186/1471-2458-8-143 [PubMed: 18445258]

Luchters SM, Vanden Broeck D, Chersich MF, Nel A, Delva W, Mandaliya K, Temmerman M. Association of HIV infection with distribution and viral load of HPV types in Kenya: A survey with 820 female sex workers. BMC Infectious Diseases. 2010; 10(1):18.10.1186/1471-2334-10-18 [PubMed: 20102630]

Luseno WK, Wechsberg WM. Correlates of HIV testing among South African women with high sexual and substance-use risk behaviours. AIDS Care. 2009; 21:178184.10.1080/09540120802017594 [PubMed: 19229686]

Lyimo RA, de Bruin M, van den Boogaard J, Hospers HJ, van der Ven A, Mushi D. Determinants of antiretroviral therapy adherence in northern Tanzania: A comprehensive picture from the patient perspective. BMC Public Health. 2012; 12:716.10.1186/1471-2458-12-716 [PubMed: 22935331]

MacAskill S, Parkes T, Brooks O, Graham L, McAuley A, Brown A. Assessment of alcohol problems using AUDIT in a prison setting: More than an 'aye or no' question. BMC Public Health. 2011; 11:865.10.1186/1471-2458-11-865 [PubMed: 22082009]

MacPhail C, Pettifor A, Moyo W, Rees H. Factors associated with HIV testing among sexually active South African youth aged 15-24 years. AIDS Care. 2009; 21:456467.10.1080/09540120802282586 [PubMed: 19401866] 
MacPherson P, Lalloo DG, Choko AT, Mann GH, Squire SB, Mwale D, Corbett EL. Suboptimal patterns of provider initiated HIV testing and counselling, antiretroviral therapy eligibility assessment and referral in primary health clinic attendees in Blantyre, Malawi. Tropical Medicine and International Health. 2012; 17:507-517.10.1111/j.1365-3156.2011.02946.x [PubMed: 22296187]

Miller, WR.; Zweben, A.; DiClemente, CC.; Rychtarik, RG. Motivational enhancement therapy manual: A clinical research guide for therapists treating individuals with alcohol abuse and dependence. Rockville, MD: NIAAA; 1992.

Nakimuli-Mpungu E, Bass JK, Alexandre P, Mills EJ, Musisi S, Ram M, Nachega JB. Depression, alcohol use and adherence to antiretroviral therapy in sub-Saharan Africa: A systematic review. AIDS and Behavior. 2012; 16:2101-2118.10.1007/s10461-011-0087-8 [PubMed: 22116638]

National AIDS and STI Control Programme, Ministry of Health, Kenya. Kenya AIDS indicator survey 2012: Preliminary report. Nairobi, Kenya: Ministry of Health; 2013 Sep.

Ohl ME, Perencevich E, McInnes DK, Kim N, Rimland D, Akgun K, Justice A. Antiretroviral adherence among rural compared to urban veterans with HIV infection in the United States. AIDS and Behavior. 2013; 17(1):174-180.10.1007/s10461-012-0325-8 [PubMed: 23080359]

Peltzer K, Mlambo G. Factors determining HIV viral testing of infants in the context of mother-tochild transmission. Acta Paediatrica (Oslo, Norway: 1992). 2010; 99:590-596.10.1111/j. 1651-2227.2009.01670.x

Pitpitan EV, Kalichman SC, Eaton LA, Sikkema KJ, Watt MH, Skinner D. Gender-based violence and HIV sexual risk behavior: Alcohol use and mental health problems as mediators among women in drinking venues, Cape Town. Social Science \& Medicine (1982). 2012; 75:1417-1425.10.1016/ j.socscimed.2012.06.020 [PubMed: 22832324]

Rosen S, Fox MP. Retention in HIV care between testing and treatment in sub-Saharan Africa: A systematic review. PLoS Medicine. 2011; 8:e1001056.10.1371/journal.pmed.1001056 [PubMed: 21811403]

Saunders JB, Aasland OG, Babor TF, de la Fuente JR, Grant M. Development of the alcohol use disorders identification test (AUDIT): WHO collaborative project on early detection of persons with harmful alcohol consumption-II. Addiction (Abingdon, England). 1993; 88:791-804.

van der Elst EM, Okuku HS, Nakamya P, Muhaari A, Davies A, McClelland RS, Sanders EJ. Is audio computer-assisted self-interview (ACASI) useful in risk behaviour assessment of female and male sex workers, Mombasa, Kenya? PloS One. 2009; 4:e5340.10.1371/journal.pone.0005340 [PubMed: 19412535]

Weiser SD, Leiter K, Heisler M, McFarland W, Korte FP, DeMonner SM, Bangsberg DR. A population-based study on alcohol and high-risk sexual behaviors in Botswana. PLoS Medicine. 2006; 3:e392.10.1371/journal.pmed.0030392 [PubMed: 17032060]

World Health Organization. Toolkit for targeted HIV/AIDS prevention and care in sex work setting. 2005. Retrieved July 30, 2013, from http://whqlibdoc.who.int/publications/2005/9241592966.pdf

World Health Organization, Department of Mental Health and Substance Dependence. Surveys of drinking patterns and problems in seven developing countries. 2000. Retrieved July 30, 2013, from http://www.unicri.it/min.san.bollettino/dati/AlcBrochur.pdf

Xu J, Brown K, Ding G, Wang H, Zhang G, Reilly K, Wang N. Factors associated with HIV testing history and HIV-test result follow-up among female sex workers in two cities in Yunnan, China. Sexually Transmitted Diseases. 2011; 38(2):89-95.10.1097/OLQ.0b013e3181f0bc5e [PubMed: 20838364]

Zablotska IB, Gray RH, Serwadda D, Nalugoda F, Kigozi G, Sewankambo N, Wawer M. AIDS (London, England). 2006; 20:1191-1196.10.1097/01.aids.0000226960.25589.72 


\section{Table 1}

Baseline alcohol use, demographic, and sexual behavior characteristics of 818 FSWs in Mombasa, Kenya, by HIV testing status.

\begin{tabular}{|c|c|c|c|}
\hline Characteristics & $\begin{array}{l}\text { Never tested for HIV } N(\%) \\
\qquad N=93(11.4)\end{array}$ & $\begin{array}{c}\text { Ever tested for HIV } N(\%) \\
\quad N=724(88.6)\end{array}$ & $\begin{array}{c}\text { Total } N(\%) \\
N=818\end{array}$ \\
\hline \multicolumn{4}{|l|}{ Alcohol use } \\
\hline Hazardous drinking (AUDIT 7-15) & $51(54.8)$ & $477(65.8)$ & $528(64.6)$ \\
\hline Harmful drinking (AUDIT 16-19) & $42(45.2)$ & $248(34.2)$ & $290(35.5)$ \\
\hline \multicolumn{4}{|l|}{ Age (years) } \\
\hline $18-23$ & $30(32.3)$ & $215(29.7)$ & $245(30.0)$ \\
\hline $24-26$ & $14(15.1)$ & $193(26.6)$ & $207(25.3)$ \\
\hline $27-30$ & $14(15.1)$ & 149 (20.6) & $163(19.9)$ \\
\hline $31-54$ & $35(37.6)$ & $168(23.2)$ & $203(24.8)$ \\
\hline \multicolumn{4}{|l|}{ Education } \\
\hline Never attended school or primary school, any & $52(55.9)$ & $397(54.8)$ & 449 (54.9) \\
\hline Secondary or post-secondary school, any & $41(44.1)$ & $328(45.2)$ & $369(45.1)$ \\
\hline \multicolumn{4}{|l|}{ Number of children ${ }^{a}$} \\
\hline No children & $24(25.8)$ & $101(13.9)$ & $125(15.3)$ \\
\hline$\geq 1$ child & $65(69.9)$ & $597(82.3)$ & $662(80.9)$ \\
\hline \multicolumn{4}{|l|}{ Number of sexual partners in the last 7 days ${ }^{a}$} \\
\hline $0-2$ & $52(55.9)$ & $421(58.1)$ & $473(57.8)$ \\
\hline $3+$ & $37(39.8)$ & $278(38.3)$ & $315(38.5)$ \\
\hline \multicolumn{4}{|l|}{ Number of years as a FSW } \\
\hline ㄴ.50 & $29(31.2)$ & $180(24.8)$ & 209 (25.6) \\
\hline $2.51-4.00$ & $16(17.2)$ & $188(25.9)$ & $204(24.9)$ \\
\hline $4.01-7.00$ & $19(20.4)$ & $186(25.7)$ & $205(25.1)$ \\
\hline$>7.00$ & $29(31.2)$ & $171(23.6)$ & $200(24.5)$ \\
\hline \multicolumn{4}{|l|}{ HIV status } \\
\hline Negative & $66(71.0)$ & $586(80.8)$ & $652(79.7)$ \\
\hline Positive & $27(29.0)$ & $139(19.2)$ & $166(20.3)$ \\
\hline
\end{tabular}

${ }^{a}$ Missing data by variable and HIV testing history: number of children: 4 (4.3\%) never tested, 27 (3.7\%) tested; number of sexual partners in the last 7 days: $4(4.3 \%)$ never tested, $26(3.6 \%)$ tested. 
Table 2

Multivariable analysis of alcohol use and having never tested for HIV among FSWs in Mombasa, Kenya.

\begin{tabular}{|c|c|}
\hline & $\operatorname{PR}(95 \% \mathrm{CI})^{a}$ \\
\hline \multicolumn{2}{|l|}{ Alcohol use } \\
\hline Hazardous drinking (AUDIT 7-15) & 1.00 \\
\hline Harmful drinking (AUDIT 16-19) & $1.60(1.07,2.40)^{b}$ \\
\hline \multicolumn{2}{|l|}{ Age (years) } \\
\hline $18-23$ & 1.00 \\
\hline $24-26$ & $0.87(0.46,1.63)$ \\
\hline $27-30$ & $1.07(0.55,2.10)$ \\
\hline $31-54$ & $1.98(1.06,3.70)^{b}$ \\
\hline \multicolumn{2}{|l|}{ Education } \\
\hline Never attended school or primary school, any & 1.00 \\
\hline Secondary or post-secondary school, any & $0.85(0.56,1.30)$ \\
\hline \multicolumn{2}{|l|}{ Number of children } \\
\hline No children & 1.00 \\
\hline$\geq 1$ child & $0.39(0.24,0.64)^{b}$ \\
\hline \multicolumn{2}{|l|}{ Number of sexual partners in the last 7 days } \\
\hline $0-2$ & 1.00 \\
\hline $3+$ & $1.11(0.73,1.67)$ \\
\hline \multicolumn{2}{|l|}{ Number of years as a FSW } \\
\hline ㄴ.50 & 1.00 \\
\hline $2.51-4.00$ & $0.65(0.36,1.17)$ \\
\hline $4.01-7.00$ & $0.65(0.37,1.13)$ \\
\hline$>7.00$ & $0.77(0.43,1.38)$ \\
\hline \multicolumn{2}{|l|}{ HIV status } \\
\hline Negative & 1.00 \\
\hline Positive & $1.38(0.85,2.25)$ \\
\hline
\end{tabular}

${ }^{a}$ Prevalence ratios adjusted for drop-in center and all other variables in the table.

$b_{\text {Indicates significant at the } 0.05 \text { level. }}$ 